\title{
Enhancement of $5-\mathrm{HT}_{2 \mathrm{~A}}$ receptor function and blockade of Kv1.5 by MK801 and ketamine: implications for PCP derivative- induced disease models
}

\author{
Haiyue Lin ${ }^{1,2,7}$, Jae Gon Kim', Sang Woong Park ${ }^{3}$, Hyun Ju Noh', Jeong Min Kim', Chang Yong Yoon ${ }^{4}$, Nam-Sik Woo ${ }^{4}$,
} Bokyung Kim', Sung $\| \mathrm{Cho}^{1}$, Bok Hee Choi ${ }^{5}$, Dong Jun Sung $\mathbb{0}^{6}$ and Young Min Bae ${ }^{1}$

\begin{abstract}
MK801 and ketamine, which are phencyclidine (PCP) derivative N-methyl-d-aspartate receptor (NMDAr) blockers, reportedly enhance the function of 5-hydroxytryptamine ( $\mathrm{HT})-2 \mathrm{~A}$ receptors $\left(5-\mathrm{HT}_{2 \mathrm{~A}} \mathrm{Rs}\right)$. Both are believed to directly affect the pathogenesis of schizophrenia, as well as hypertension. $5-\mathrm{HT}_{2 \mathrm{~A}} \mathrm{R}$ signaling involves the inhibition of $\mathrm{KV}$ conductance. This study investigated the interaction of these drugs with $\mathrm{Kv} 1.5$, which plays important roles in $5-\mathrm{HT}_{2 \mathrm{~A}} \mathrm{R}$ signaling and in regulating the excitability of the cardiovascular and nervous system, and the potential role of this interaction in the enhancement of the $5-\mathrm{HT}_{2 \mathrm{~A}} \mathrm{R}$-mediated response. Using isometric organ bath experiments with arterial rings and conventional whole-cell patch-clamp recording of Chinese hamster ovary (CHO) cells ectopically overexpressing Kv1.5, we examined the effect of ketamine and MK801 on 5-HT $2 \mathrm{~A}$-mediated vasocontraction and Kv1.5 channels. Both ketamine and MK801 potentiated 5- $\mathrm{HT}_{2 \mathrm{~A}} \mathrm{R}$-mediated vasocontraction. This potentiation of 5$H T_{2 A} \mathrm{R}$ function occurred in a membrane potential-dependent manner, indicating the involvement of ion channel(s). Both ketamine and MK801 rapidly and directly inhibited Kv1.5 channels from the extracellular side independently of NMDArs. The potencies of MK801 in facilitating the $5-\mathrm{HT}_{2 \mathrm{~A}} \mathrm{R}$-mediated response and blocking Kv1.5 were higher than those of ketamine. Our data demonstrated the direct inhibition of Kv1.5 channels by MK801/ketamine and indicated that this inhibition may potentiate the functions of $5-\mathrm{HT}_{2 \mathrm{~A}} \mathrm{Rs}$. We suggest that $5-\mathrm{HT}_{2 \mathrm{~A}} \mathrm{R}-\mathrm{Kv} 1.5$ may serve as a receptoreffector module in response to 5 -HT and is a promising target in the pathogenesis of MK801-/ketamine-induced disease states such as hypertension and schizophrenia.
\end{abstract}

\section{Introduction}

MK801 and ketamine are derivatives of phencyclidine (PCP), which is also known as angel dust ${ }^{1,2}$. These PCPrelated drugs are well known to block the ionotropic N-

\footnotetext{
Correspondence: Young Min. Bae (ymbae30@kku.ac.kr)

'Department of Physiology, KU Open Innovation Center, Research Institute of Medical Science, Konkuk University School of Medicine, Chungju, Chungbuk 27478, South Korea

2Department of Physiology, Seoul National University, College of Medicine, Seoul 03080, South Korea

Full list of author information is available at the end of the article

These authors contributed equally: H Lin, JG Kim, SW Park.
}

methyl-d-aspartate receptor (NMDAr) by noncompetitively binding to the internal ionic pore region of NMDAr ${ }^{1-3}$. These PCP-related NMDAr antagonists have been reported to induce various clinical symptoms, such as psychosis, schizophrenia, and hypertension. However, the mechanisms underlying these symptoms are unclear and controversial ${ }^{4-7}$. The direct effects of ketamine and PCP on dopamine $\mathrm{D}_{2}$ and serotonin 5hydroxytryptamine $(\mathrm{HT})_{2}$ receptors have been suggested to be implicated in the pathogenesis of schizophrenia ${ }^{8-11}$. In agreement with this, a previous study showed that

\section{(c) The Author(s) 2018}

\footnotetext{
Open Access This article is licensed under a Creative Commons Attribution-NonCommercial-ShareAlike 4.0 International License, which permits any non-commercial use, cc. sh ${ }_{\text {NG SA }}$ sharing, adaptation, distribution and reproduction in any medium or format, as long as you give appropriate credit to the original author(s) and the source, provide a link to the Creative Commons license, and indicate if changes were made. If you remix, transform, or build upon this article or a part thereof, you must distribute your contributions under the same license as the original. The images or other third party material in this article are included in the article's Creative Commons license, unless indicated otherwise in a credit line to the material. If material is not included in the article's Creative Commons license and your intended use is not permitted by statutory regulation or exceeds the permitted use, you will need to obtain permission directly from the copyright holder. To view a copy of this license, visit http://creativecommons.org/licenses/by-nc-sa/4.0/.
} 
$5-\mathrm{HT}_{2 \mathrm{~A}}$ receptor $\left(5-\mathrm{HT}_{2 \mathrm{~A}} \mathrm{R}\right)$-mediated arterial contraction was facilitated by ketamine ${ }^{12}$, which was suggested to be the mechanism underlying ketamine-induced hypertension. In addition, NMDAr antagonists, including MK801 and ketamine, enhanced the head-twitch response, a 5-HT2R-mediated behavior, in reserpinetreated mice ${ }^{13}$.

Voltage-gated $\mathrm{K}^{+}$channel $(\mathrm{Kv})$ currents in arterial smooth muscle cells have been reported to be blocked by ketamine and MK801 ${ }^{14,15}$. However, reports on the effects of MK801 or ketamine on the specific subtype(s) of Kv are not available yet. Because $\mathrm{Kv}$ channels such as Kv1.5 in the arterial smooth muscle play a critical role in $5-\mathrm{HT}_{2 \mathrm{~A}} \mathrm{R}$ signaling $^{16-18}$, whether Kv1.5 is blocked by MK801 and ketamine is worth examining. Moreover, Kv1.5 plays critical roles in regulating the membrane excitabilities of atrial cardiomyocytes $^{19,20}$ and several neuronal and glial cells, such as pituitary neurons and Schwann cells ${ }^{21,22}$. In this study, we report that MK801 and ketamine facilitated the response of $5-\mathrm{HT}_{2 \mathrm{~A}} \mathrm{R}$ activation in a membrane potential $\left(\mathrm{E}_{\mathrm{m}}\right)$-dependent manner and directly blocked Kv1.5 channels from the extracellular side. From these findings, we suggest that $5-\mathrm{HT}_{2 \mathrm{~A}} \mathrm{R}-\mathrm{Kv} 1.5$ may play an important role as a receptor-effector module in response to 5 -HT. Moreover, $5-\mathrm{HT}_{2 \mathrm{~A}} \mathrm{R}-\mathrm{Kv} 1.5$ is a promising target of MK801 and ketamine in the pathogenesis of clinical symptoms induced by these PCP derivative NMDAr antagonists.

\section{Materials and methods}

\section{Animals and tissue preparation}

All experiments were conducted in accordance with the National Institutes of Health guidelines for the care and use of animals. The Institutional Animal Care and Use Committee of Konkuk University approved this study. Mesenteric arterial rings and aorta rings were prepared, as previously described ${ }^{17,23}$. The carotid arteries of male Sprague-Dawley (SD) rats (10-11 weeks old) were cut to exsanguinate the rats under deep ketamine-xylazine anesthesia or after exposure to $100 \%$ carbon dioxide. The branches of the superior mesenteric arteries and thoracic aorta were promptly isolated and placed in physiological saline solution (PSS) containing $136.9 \mathrm{mM} \mathrm{NaCl}, 5.4 \mathrm{mM}$ $\mathrm{KCl}, 1.5 \mathrm{mM} \mathrm{CaCl}_{2}, 1.0 \mathrm{mM} \mathrm{MgCl} 2,23.8 \mathrm{mM} \mathrm{NaHCO}{ }_{3}$, $1.2 \mathrm{mM} \mathrm{NaH} \mathrm{PO}_{4}, \quad 0.01 \mathrm{mM}$ ethylenediaminetetraacetic acid (EDTA), and $5.5 \mathrm{mM}$ glucose. The arteries were carefully cleaned of fat and connective tissues under a stereomicroscope and prepared as rings (3.5 $\mathrm{mm}$ in length) for tension measurements. The endothelium was mechanically removed with a fine stainless-steel wire. The endothelial removal was confirmed by the absence of relaxation induced by acetylcholine $(10 \mu \mathrm{M})$ after norepinephrine (NE; $1-10 \mu \mathrm{M})$ or 5-HT (1-10 $\mu \mathrm{M})$-induced contraction.

\section{Tension measurements}

The isometric tension of the arterial rings was measured, as previously described ${ }^{17,23}$. The arterial rings were mounted vertically on two L-shaped stainless-steel wires in a 3-mL tissue chamber. One wire was attached to a micromanipulator and the other to an isometric force transducer (FT03; Grass, West Warwick, RI, USA). The changes in isometric force were digitally acquired at $1 \mathrm{~Hz}$ with a PowerLab data acquisition system (ADInstruments, Colorado Springs, CO, USA). Resting tension was set to 1 $\mathrm{g}$ (mesenteric arterial rings) or $2 \mathrm{~g}$ (aorta) by the micromanipulator. After equilibration for $60 \mathrm{~min}$ under resting tension in a tissue chamber filled with PSS, the rings were sequentially exposed to $70 \mathrm{mM} \mathrm{KCl} \mathrm{PSS} \mathrm{(10} \mathrm{min)} \mathrm{and} \mathrm{PSS}$ (15 min) thrice for stabilization. High $\mathrm{KCl}(70 \mathrm{mM})$ PSS was prepared by replacing $\mathrm{NaCl}$ with equimolar $\mathrm{KCl}$ in PSS. The bathing solutions were thermostatically controlled at $37^{\circ} \mathrm{C}$ and continuously saturated with a mixture of $95 \% \mathrm{O}_{2}$ and $5 \% \mathrm{CO}_{2}$ to achieve a $\mathrm{pH}$ of 7.4 .

\section{Cell culture and transfection}

Chinese hamster ovary (CHO) cells expressing Kv1.5 derived from the rat brain were used for electrophysiological recordings ${ }^{24,25}$. Kv1.5 cDNA $^{26}$ was transferred into the plasmid expression vector pCR3.1 (Invitrogen Corporation, San Diego, CA, USA). CHO cells were transfected with Kv1.5 cDNA using FuGENE ${ }^{\mathrm{mm}} 6$ reagent (Boehringer Mannheim, Indianapolis, IN, USA). The transfected cells were cultured in Iscove's modified Dulbecco's medium (Invitrogen Corporation) supplemented with $10 \%$ fetal bovine serum, $2 \mathrm{mM}$ glutamine, $0.1 \mathrm{mM}$ hypoxanthine, $0.01 \mathrm{mM}$ thymidine, and $300 \mu \mathrm{g} /$ mL G418 (A.G. Scientific, San Diego, CA, USA) in a 95\% humidified air-5\% $\mathrm{CO}_{2}$ incubator at $37^{\circ} \mathrm{C}$. The cultures were passaged every $4-5$ days with a brief trypsin-EDTA treatment and then seeded onto glass coverslips (diameter: $12 \mathrm{~mm}$, Fisher Scientific, Pittsburgh, PA, USA) in a Petri dish. After 12-24 h, the cell-attached coverslips were used for electrophysiological recordings.

\section{Electrophysiology}

Kv1.5 currents were recorded from $\mathrm{CHO}$ cells using the whole-cell patch-clamp technique ${ }^{27}$ at room temperature $\left(22-23^{\circ} \mathrm{C}\right)$. Micropipettes fabricated from glass capillary tubing (PG10165-4; World Precision Instruments, Sarasota, FL, USA) with a double-stage vertical puller (PC-10; Narishige, Tokyo) had a tip resistance of $2-3 \mathrm{M} \Omega$ when filled with the pipette solution. Whole-cell currents were amplified with an Axopatch 200 B amplifier (Molecular Devices, Sunnyvale, CA, USA), digitized with the Digidata 1440 A (Molecular Devices) at $5 \mathrm{kHz}$, and low-pass filtered with a four-pole Bessel filter at $2 \mathrm{kHz}$. Capacitive 
currents were canceled, and series resistance was compensated at $80 \%$ with the amplifier, while leak subtraction was not used. The generation of voltage commands and acquisition of data were controlled with pClamp 10.1 software (Molecular Devices) running on an IBMcompatible Pentium computer. The recording chamber (RC-11, Warner Instrument Corporation, Hamden, CT, USA) was continuously perfused with the bath solution (see below for composition) at a rate of $1 \mathrm{~mL} / \mathrm{min}$.

The intracellular pipette solution for whole-cell recordings contained $140 \mathrm{mM} \mathrm{KCl}, 5 \mathrm{mM} \mathrm{NaCl}, 5 \mathrm{mM}$ MgATP, $10 \mathrm{mM}$ 4-(2-hydroxyethyl)-1-piperazine ethane sulfonic acid (HEPES), and $10 \mathrm{mM} \mathrm{1,2-bis(o-aminophe-}$ noxy)ethane- $\mathrm{N}, \mathrm{N}, \mathrm{N}^{\prime}, \mathrm{N}^{\prime}$-tetraacetic acid (BAPTA) and was adjusted to a $\mathrm{pH}$ of 7.2 with $\mathrm{KOH}$. The bath solution for whole-cell recordings contained $143 \mathrm{mM} \mathrm{NaCl}, 5.4 \mathrm{mM}$ $\mathrm{KCl}, 0.33 \mathrm{mM} \mathrm{NaH} \mathrm{PO}_{4}, 1.8 \mathrm{mM} \mathrm{CaCl} 2,0.5 \mathrm{mM} \mathrm{MgCl}$, $5 \mathrm{mM}$ HEPES, and $11 \mathrm{mM}$ glucose and was adjusted to a $\mathrm{pH}$ of 7.35-7.40 with $\mathrm{NaOH}$.

\section{Drugs}

All chemicals, including ketamine and MK801, were purchased from Sigma-Aldrich (St. Louis, MO, USA).

\section{Data analysis}

Origin 8.0 software (Microcal Software, Inc., Northampton, MA, USA) was used for data analysis. The results are shown as the means \pm SEM. Paired or independent Student's $t$-tests were performed to test for significance as appropriate, and $p<0.05$ was regarded as significant. For analysis of the concentration-response curves (CRCs), Student's $t$-tests were performed at a given concentration to compare the two groups. When the two groups were not statistically different at any given concentration, the differences in the CRCs were determined to be N.S. (not significant) (Fig. 1c-e, g, and Fig. 2c).

\section{Results}

\section{Em-dependent facilitation of the 5-HT2AR-mediated} arterial contraction induced by MK801 and ketamine

$5-\mathrm{HT}_{2 \mathrm{~A}} \mathrm{Rs}$ have been previously reported to mediate the effect of 5 -HT in rat mesenteric arteries ${ }^{17}$, and ketamine has been shown to facilitate $5-\mathrm{HT}_{2 \mathrm{~A}} \mathrm{R}$-mediated contraction without unmasking other subtypes of 5-HT receptors, such as 5 -HT1B or 5 -HT2B receptors ${ }^{12}$. In this study, we examined whether MK801, another PCP derivative, also has similar effects on $5-\mathrm{HT}_{2 \mathrm{~A}} \mathrm{R}$-mediated arterial contraction. The CRC of 5-HT-induced contraction of rat mesenteric arteries was evidently shifted to the left in the presence of MK801 (10 $\mu \mathrm{M}$, Fig. 1a), indicating that MK801 also facilitated the $5-\mathrm{HT}_{2 \mathrm{~A}} \mathrm{R}$-mediated response in rat mesenteric arteries. Furthermore, in the presence of a physiologically relevant concentration of 5HT (200 nM, which is close to the resting plasma level of
5-HT), MK801 contracted the mesenteric arterial rings (Fig. 1b) in a concentration-dependent manner. However, MK801 alone, similar to ketamine ${ }^{12}$, had a negligible effect on arterial contraction in the control condition without 5-HT (Fig. 1f). The CRCs of MK801-induced arterial contractions in the presence of $200 \mathrm{nM} \alpha$-methyl 5 -HT, which is a selective agonist of 5-HT2Rs, were similar between the $(+)$ and $(-)$ MK801 enantiomers (Fig. 1c), although the potencies of these optical isomers in blocking NMDArs are known to be quite different ${ }^{1,2}$.

To further examine whether this facilitating effect of MK801 on $5-\mathrm{HT}_{2 \mathrm{~A}} \mathrm{R}$-mediated arterial contraction is related to ion channel regulation, we examined the effect of MK801 on $\mathrm{E}_{\mathrm{m}}$-independent arterial contraction. The $\mathrm{E}_{\mathrm{m}}$-independent arterial contraction was isolated by pretreatment of the arterial rings with both nifedipine $(1 \mu \mathrm{M})$ and high $\mathrm{KCl}(70 \mathrm{mM})^{17}$. Notably, the left shift of the CRC of the $5-\mathrm{HT}_{2 \mathrm{~A}} \mathrm{R}$-mediated arterial contraction by MK801 was not observed when the $\mathrm{E}_{\mathrm{m}}$-dependent 5 - $\mathrm{HT}$ response was excluded (Fig. 1d). Similarly, the facilitating effect of ketamine $^{12}$ was not observed when the $\mathrm{E}_{\mathrm{m}}$-dependent 5HT response was excluded (Fig. 1e). These results suggest that the PCP derivatives MK801 and ketamine facilitate the $5-\mathrm{HT}_{2 \mathrm{~A}} \mathrm{R}$-mediated response by regulating ion channels and $E_{m}$. In support of this $E_{m}$-dependent facilitation hypothesis, MK801 did not contract the high $(70 \mathrm{mM})$ $\mathrm{KCl}$-precontracted arterial rings (Fig. 1f).

To define whether the facilitating effects of MK801 on arterial contraction were receptor-specific, we further examined the effect of MK801 on the CRCs of phenylephrine-induced vasocontraction. In contrast to the contractions induced by $5-\mathrm{HT}, \mathrm{MK} 801$ had negligible effects on the CRCs of phenylephrine-induced vasocontraction (Fig. 1g).

\section{Direct inhibition of Kv1.5 by MK801 and ketamine from the extracellular side}

The response of $5-\mathrm{HT}_{2 \mathrm{~A}}$ Rs is mediated by a decrease in $\mathrm{Kv}$ conductance ${ }^{9,16-18}$. Noticeably, hallucinogens other than PCP derivatives (such as LSD) have also been reported to modulate $\mathrm{Kv}$ channel activity, acting at 5HT2Rs ${ }^{9}$. In particular, Kv1.5 has been reported to be primarily responsible for mediating $5-\mathrm{HT}_{2 \mathrm{~A}} \mathrm{R}$ activation in the arteries ${ }^{18}$. If MK801 and ketamine inhibit Kv1.5, these drugs could be hypothesized to augment $5-\mathrm{HT}_{2 \mathrm{~A}} \mathrm{R}$ signaling by facilitating $5-\mathrm{HT}_{2 \mathrm{~A}} \mathrm{R}$-mediated $\mathrm{Kv} 1.5$ inhibition and $\mathrm{E}_{\mathrm{m}}$ depolarization. To address this hypothesis, we examined the effect of MK801 on Kv1.5 currents in CHO cells stably overexpressing Kv1.5. MK801 concentrationdependently $\quad\left[\mathrm{IC}_{50}=156.8 \pm 7.9 \mu \mathrm{M}\right.$, Hill coefficient $=$ $1.03 \pm 0.05$ for $(-) \mathrm{MK} 801 ; \mathrm{IC}_{50}=157.3 \pm 14.0 \mu \mathrm{M}$, Hill coefficient $=0.93 \pm 0.03$ for $(+)$ MK801] inhibited Kv1.5 currents (Fig. 2a-c). The inhibition of Kv1.5 currents upon MK801 application was rapid and reversible 

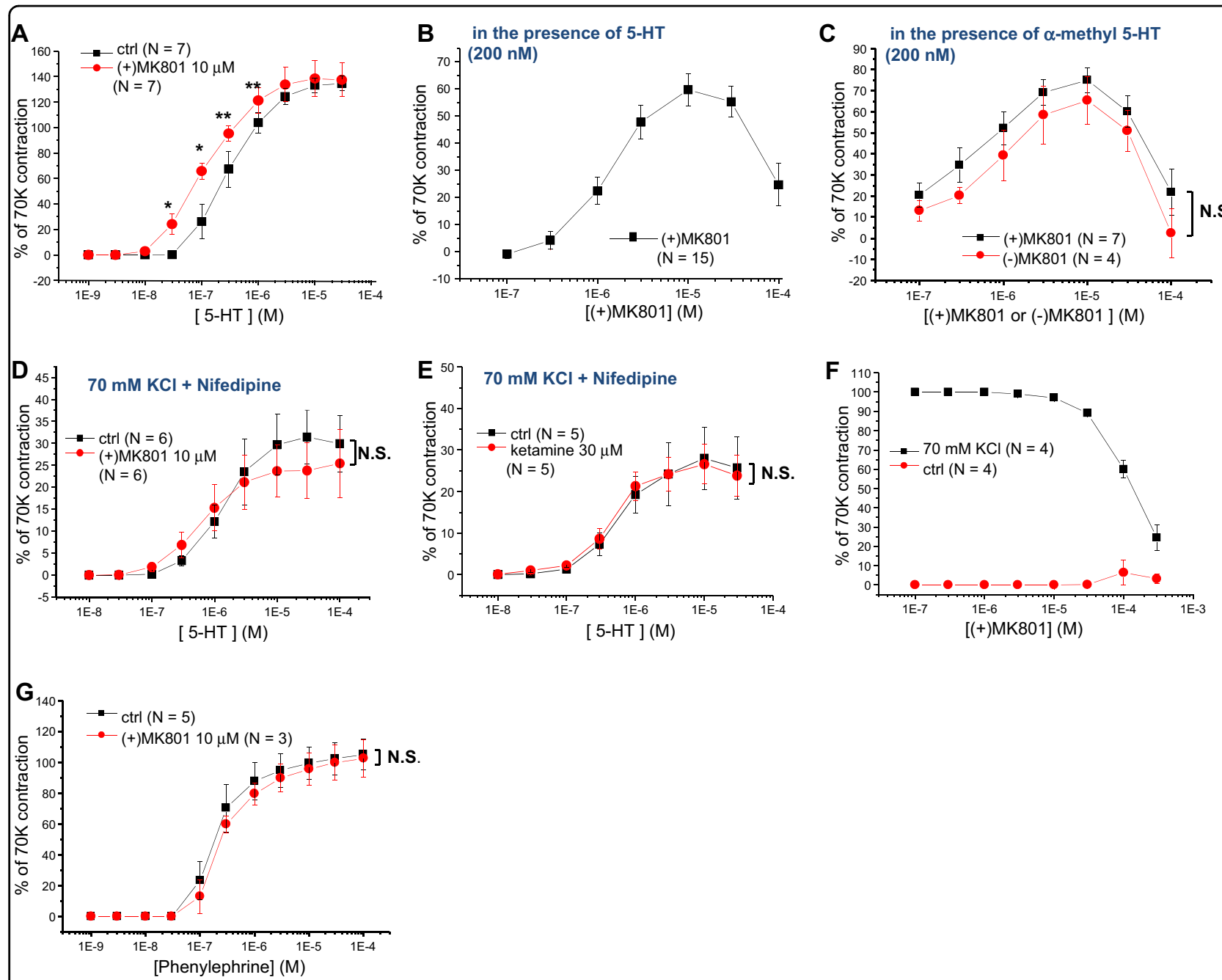

Fig. 1 Facilitation of $5-\mathrm{HT}_{2 \mathrm{~A}} \mathrm{R}$-mediated arterial contractions by MK801 and ketamine. a Concentration-response curves (CRCS) of 5-HT-induced rat mesenteric arterial contractions in the absence and presence of MK801. b CRC of MK801-induced rat mesenteric arterial contractions in the presence of a physiological concentration (200 nM) of 5-HT. c CRC of (+) and (-) MK801-induced rat mesenteric arterial contractions in the presence of $200 \mathrm{nM}$ of a-methyl 5-HT, a selective 5- $\mathrm{HT}_{2 \mathrm{~A}} \mathrm{R}$ agonist. $\mathbf{d}$ Membrane potential $\left(\mathrm{E}_{\mathrm{m}}\right)$-independent $\mathrm{CRCs}$ of 5-HT-induced rat mesenteric arterial contractions in the absence and presence of MK801 after pretreatment with $70 \mathrm{mM} \mathrm{KCl}$ and nifedipine $(1 \mu \mathrm{M})$. e $\mathrm{E}_{\mathrm{m}}$-independent CRCs of 5-HTinduced rat mesenteric arterial contractions in the absence and presence of ketamine after pretreatment with $70 \mathrm{mM} \mathrm{KCl}$ and nifedipine $(1 \mu \mathrm{M})$. $\mathbf{f} C R C$ of MK801-induced rat mesenteric arterial contractions in the absence and presence of high $(70 \mathrm{mM}) \mathrm{KCl}$. $\mathbf{g} \mathrm{CRCs}$ of phenylephrine-induced rat aorta contractions in the absence and presence of MK801. N in parentheses indicates the number of animals examined. ${ }^{*} p<0.05 ;{ }^{*} p<0.01$; N.S. not significant

(Fig. 2b). The optical isomers of MK801 $[(+)$ and (-) MK801] inhibited Kv1.5 currents with similar potency and efficacy (Fig. 2a, c).

To determine whether MK801 blocks Kv1.5 from the extracellular or intracellular side, we examined the effect of MK801 using a pipette containing MK801. When the Kv1.5 currents were recorded with a pipette containing MK801 (up to $1 \mathrm{mM}$ ), the amplitudes of Kv1.5 currents were still comparable to those recorded under the control condition without MK801 in the pipette (Fig. 3). Moreover, Kv1.5 current inhibition by the bath application of
MK801 was not affected by MK801 in the pipette (Fig. 2a, c). These results indicate that MK801 inhibited Kv1.5 from the extracellular side.

Similarly, ketamine $[(+)$ and $(-)$ racemate] inhibited Kv1.5 from the extracellular side (Fig. 4a). The ketamineinduced Kv1.5 inhibition was also rapid and reversible after wash-out (Fig. 4b). The potency of ketamine in inducing Kv1.5 inhibition was relatively lower than that of MK801 $\left(\mathrm{IC}_{50}=640.5 \pm 33.2 \mu \mathrm{M}\right.$, Hill coefficient $=1.12 \pm$ 0.06, Fig. 4a-c). 

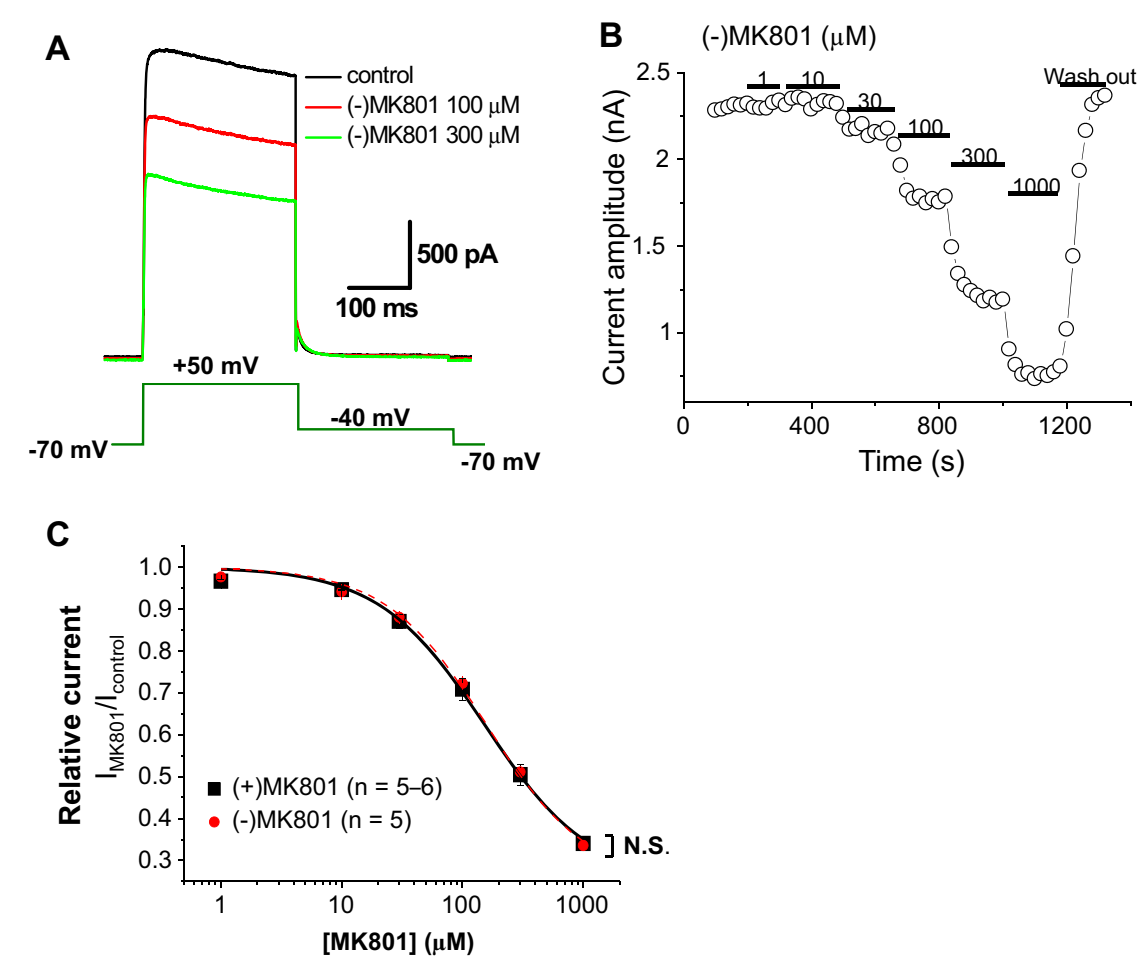

Fig. 2 Inhibition of Kv1.5 currents by MK801 enantiomers recorded from CHO cells overexpressing Kv1.5. a Representative Kv1.5 current tracings elicited by voltage steps shown in the figure inset in the absence and presence of MK801 (100 and $300 \mu \mathrm{M})$. b Kv 1.5 current amplitudes at + $50 \mathrm{mV}$ are plotted against time. The period of application of various concentrations of MK801 is indicated as solid bars. c CRCs of (+) and (-) MK801 enantiomer-induced Kv1.5 inhibition. N in parentheses indicates the number of cells examined. N.S. not significant

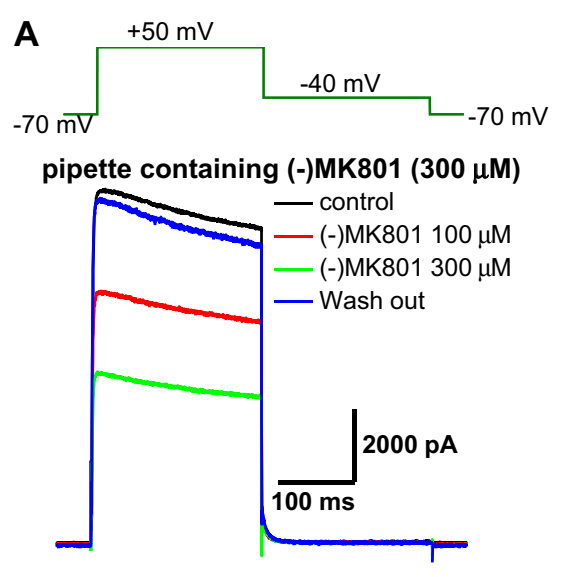

B

pipette containing (-)MK801 (1 mM)

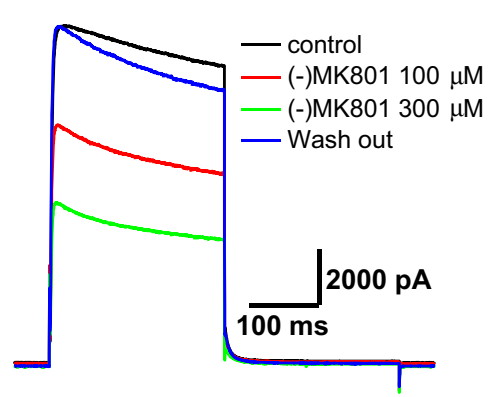

Fig. 3 Inhibition of Kv1.5 currents by extracellular MK801 recorded with MK801-containing pipettes. a Representative Kv1.5 current tracings elicited by voltage steps shown in the figure inset with the pipette containing $300 \mu \mathrm{M}$ MK801 in the absence and presence of various concentrations of MK801 in the bath. b Representative Kv1.5 current tracings with the pipette containing 1 mM MK801 in the absence and presence of various concentrations of MK801 in the bath. Similar results from 3 further independent experiments

\section{Discussion}

In our previous study, we reported that ketamine facilitated $5-\mathrm{HT}_{2 \mathrm{~A}} \mathrm{R}$-mediated arterial contraction ${ }^{12}$. The findings of this study further demonstrated that MK801, another PCP derivative NMDAr antagonist, also similarly facilitated $5-\mathrm{HT}_{2 \mathrm{~A}} \mathrm{R}$-mediated arterial contraction. The facilitation of $5-\mathrm{HT}_{2 \mathrm{~A}} \mathrm{R}$-mediated arterial contraction by MK801/ketamine was $E_{m}$-dependent, indicating that ion channel regulation is critically involved. Accordingly, Kv1.5 inhibition was suggested to play a role in mediating 

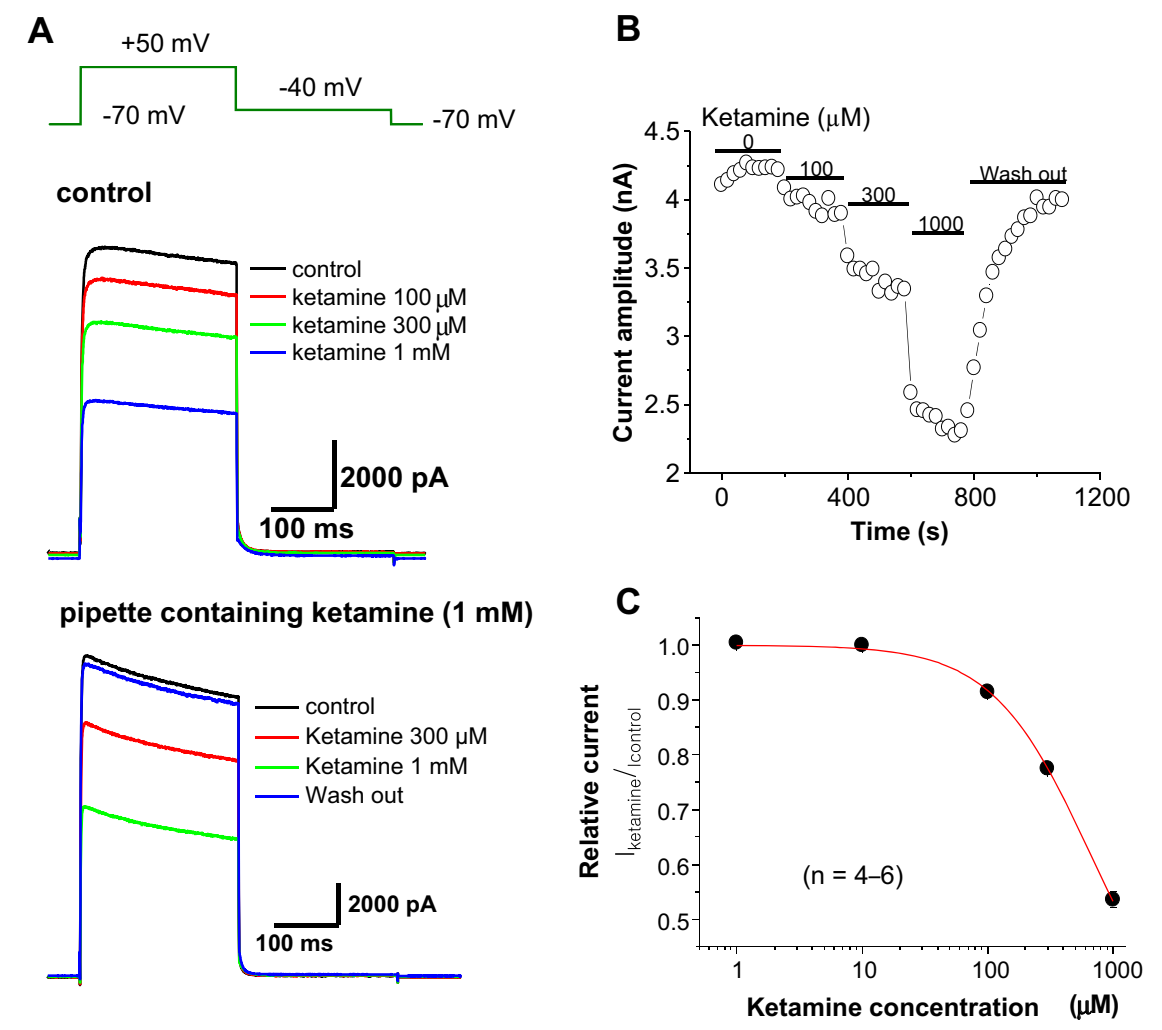

Fig. 4 Inhibition of Kv1.5 by ketamine. a (upper) Representative Kv1.5 current tracings elicited by voltage steps shown in the figure inset in the absence and presence of ketamine (100, 300, and $1000 \mu \mathrm{M})$; lower, Representative Kv1.5 current tracings recorded with the pipette containing ketamine $(1000 \mu \mathrm{M})$ in the absence and presence of bath ketamine $(100,300$, and $1000 \mu \mathrm{M})$. b Kv1.5 current amplitudes at $+50 \mathrm{mV}$ are plotted against time. The period of application of various concentrations of ketamine is indicated as solid bars. c CRCs of ketamine-induced Kv1.5 inhibition. N in parentheses indicates the number of cells examined

the facilitating effect of MK801/ketamine. To the best of our knowledge, this is the first report to show $E_{m^{-}}$ dependent facilitation of $5-\mathrm{HT}_{2 \mathrm{~A}} \mathrm{R}$-mediated arterial contraction, as well as Kv1.5 inhibition by MK801 and ketamine. We believe that the findings of this study suggest that $5-\mathrm{HT}_{2 \mathrm{~A}} \mathrm{R}-\mathrm{Kv} 1.5$ may function as an important receptor-effector module and an important target of MK801 and ketamine.

\section{Signaling of 5-HT2ARs and their regulation by MK801 and ketamine}

Neither the facilitation of the $5-\mathrm{HT}_{2 \mathrm{~A}} \mathrm{R}$ response nor the inhibition of Kv1.5 by MK801/ketamine shown in this study were related to NMDAr regulation based on the following observations: (1) MK801/ketamine inhibited $\mathrm{Kv1.5}$, which was overexpressed in $\mathrm{CHO}$ cells. (2) The inhibition of Kv1.5 by MK801 was not stereospecific, although inhibition of NMDArs by MK801 is known to be stereospecific. (3) The facilitation of $5-\mathrm{HT}_{2 \mathrm{~A}} \mathrm{R}$-mediated arterial contraction by MK801 was not stereospecific either. These observations indicate that MK801/ketamine interacted with the $5-\mathrm{HT}_{2 \mathrm{~A}} \mathrm{R}-\mathrm{Kv} 1.5$ receptor-effector module. In addition, MK801-induced facilitation was receptor-specific; $5-\mathrm{HT}_{2 \mathrm{~A}} \mathrm{Rs}$ but not $\alpha$-adrenoceptors were facilitated by MK801 (Fig. 1g).

In the rat aorta and mesenteric arteries, $5-\mathrm{HT}_{2 \mathrm{~A}} \mathrm{R}$ activation has been reported to be followed by Src phosphorylation and consequent $\mathrm{Kv}$ inhibition ${ }^{17,28}$. Because $\mathrm{Kv}$ inhibition is a downstream effector step in $5-\mathrm{HT}_{2 \mathrm{~A}} \mathrm{R}$ mediated signaling, $\sim 70 \%$ of $5-\mathrm{HT}_{2 \mathrm{~A}} \mathrm{R}$-mediated arterial contraction was dependent on $\mathrm{E}_{\mathrm{m}}$ depolarization ${ }^{17}$. In this regard, as a mechanism for MK801/ketamine-induced facilitation of $5-\mathrm{HT}_{2 \mathrm{~A}} \mathrm{Rs}$, the direct interaction of MK801 and ketamine with $5-\mathrm{HT}_{2 \mathrm{~A}} \mathrm{Rs}^{8}$ and consequent facilitation of Src phosphorylation ${ }^{17}$ could be reasoned to contribute to the MK801 and ketamine-induced facilitation of the 5$\mathrm{HT}_{2 \mathrm{~A}} \mathrm{R}$-mediated response. In agreement with this hypothesis, a previous study reported that PCP derivatives have some direct partial agonist or allosteric activator effects on 5-HT2 and D2 receptors ${ }^{8,11}$. Alternatively, as shown in this study, the direct inhibition of Kv1.5 by MK801/ketamine could potentiate the Kv1.5 inhibition mediated by $5-\mathrm{HT}_{2 \mathrm{~A}} \mathrm{R}$ activation. Notably, the facilitating concentrations of MK801 (maximal at $\sim 10 \mu \mathrm{M}$ ) and 
ketamine (maximal at $\sim 30 \mu \mathrm{M}$ ) on $5-\mathrm{HT}_{2 \mathrm{~A}}$ Rs are relatively lower than the inhibiting concentrations of MK801 and ketamine on Kv1.5 $\left(\mathrm{IC}_{50}=\sim 150\right.$ and $\sim 600 \mathrm{nM}$, respectively). The native 4-aminopyridine-sensitive $\mathrm{Kv}$ currents in the mesenteric arterial smooth muscle cells were also inhibited by MK801 and ketamine with similar potencies as the Kv1.5 current ${ }^{14,15}$. We interpreted these observations to indicate that low concentrations (around threshold for Kv1.5 inhibition) of MK801 and ketamine make Kv1.5 ready to be blocked by low concentrations of 5-HT, i.e., cooperative actions of threshold levels of 5-HT on 5$\mathrm{HT}_{2 \mathrm{~A}}$ Rs and MK801/ketamine on Kv1.5 facilitate 5-HT action. This interpretation likely explains the finding that MK801/ketamine only shifted the CRCs of 5-HT-induced arterial contraction without increasing the maximal efficacy (Fig. 1a). Furthermore, the facilitating actions of MK801 and ketamine notably occurred at their clinical concentrations with physiological concentrations of 5-HT, reinforcing their clinical relevance. At concentrations of MK801 above $30 \mu \mathrm{M}$, the facilitating effect on $5-\mathrm{HT}_{2 \mathrm{~A}} \mathrm{R}$ mediated arterial contraction was decreased (Fig. 1b, c), although the inhibitory effect on Kv1.5 became stronger (Figs. 2 and 3). A similar observation was found with ketamine ${ }^{12}$, which is probably due to some other nonspecific effect, such as inhibition of L-type voltage-gated $\mathrm{Ca}^{2+}$ channels or $\mathrm{Ca}^{2+}$-induced $\mathrm{Ca}^{2+}$ release from the sarcoplasmic reticulum ${ }^{29-31}$. In agreement, MK801 also inhibited the $70-\mathrm{mM} \mathrm{KCl}$-induced arterial contraction at concentrations above $30 \mu \mathrm{M}$ (Fig. 1f).

\section{Both MK801 and ketamine directly inhibit Kv1.5 from the extracellular side}

Although previous studies reported that MK801 and ketamine inhibited the native 4-aminopyridine-sensitive $\mathrm{Kv}$ current in dispersed rat mesenteric arterial smooth muscle cells ${ }^{14,15}$, this is the first study showing the inhibition of Kv1.5 by MK801 and ketamine. The potency of MK801 in inhibiting Kv1.5 was higher than that of ketamine. Accordingly, MK801 facilitated the $5-\mathrm{HT}_{2 \mathrm{~A}} \mathrm{R}$ response at concentrations (from $0.3 \mu \mathrm{M}$ and peak at 10 $\mu \mathrm{M}$; Fig. 1b) lower than those of ketamine (from $10 \mu \mathrm{M}$ and peak at $30 \mu \mathrm{M}$; Fig. 1a of ref. ${ }^{12}$ ). Upon application, Kv1.5 inhibition by MK801 and ketamine was very rapid and occurred from the extracellular side (Figs. 2-4), indicating that the direct inhibition of Kv1.5 by MK801 and ketamine is important in regulating the electrical excitabilities of atrial myocytes and glial and neuronal cells $^{19-22}$. In pulmonary arterial smooth muscle cells, Kv1.5 was convincingly demonstrated to be an effector of $5-\mathrm{HT}_{2 \mathrm{~A}} \mathrm{R}$ signaling ${ }^{18}$. Therefore, whether the inhibition of $\mathrm{Kv} 1.5$ and related facilitation of the $5-\mathrm{HT}_{2 \mathrm{~A}} \mathrm{R}$-induced response is involved in the pathogenesis of clinical symptoms in MK801/ketamine-induced experimental animal models of schizophrenia, hypertension, and dissociative anesthesia should be considered ${ }^{4,5,7,8,32-34}$. Notably, serotonergic mechanisms are critically involved in the pathogenesis of psychosis and schizophrenia ${ }^{6,35,36}$. The precise mechanism underlying the MK801 and ketamine-induced facilitation of $5-\mathrm{HT}_{2 \mathrm{~A}} \mathrm{Rs}$ and $\mathrm{Kv} 1.5$ inhibition and their clinical outcomes warrants future study. In addition, the effects of other Kv subtypes, such as Kv1.1, Kv1.2, and Kv1.6, and their role in the facilitation of 5-HT2Rs need to be evaluated ${ }^{9}$.

In conclusion, MK801 and ketamine facilitate the 5$\mathrm{HT}_{2 \mathrm{~A}} \mathrm{R}$ activation response in an $\mathrm{E}_{\mathrm{m}}$-dependent manner, especially at lower, physiologically relevant concentrations of 5 - HT, likely by acting on the $5-\mathrm{HT}_{2 \mathrm{~A}} \mathrm{R}-\mathrm{Kv} 1.5$ receptoreffector module, which is independent of NMDArs.

\section{Acknowledgements}

This paper was written as part of Konkuk University's research support program for its faculty on sabbatical leave in 2016. It was also supported by a grant of the Korea Health Technology R\&D Project through the Korea Health Industry Development Institute (KHIDI), funded by the Ministry of Health \& Welfare, Republic of Korea (H15C1540), and by a Basic Science Research Program (2015R1C1A1A02036887) through the National Research Foundation of Korea (NRF) funded by the Ministry of Science, ICT \& Future Planning.

\section{Author details \\ ${ }^{1}$ Department of Physiology, KU Open Innovation Center, Research Institute of Medical Science, Konkuk University School of Medicine, Chungju, Chungbuk 27478, South Korea. ${ }^{2}$ Department of Physiology, Seoul National University, College of Medicine, Seoul 03080, South Korea. ${ }^{3}$ Department of Emergency Medical Services, Eulji University, Seongnam, Gyeonggi-do 13135, South Korea. ${ }^{4}$ Department of Anesthesiology, Konkuk University School of Medicine, Konkuk University Medical Center, Seoul 05030, South Korea. ${ }^{5}$ Department of Pharmacology, Institute for Medical Science, Chonbuk National University Medical School, Jeonju, Jeonbuk 54097, South Korea. ${ }^{6}$ Sports and Health Studies, College of Biomedical and Health Science, Konkuk University, Seoul 27478, South Korea. . ${ }^{7}$ Present address: Department of Physiology, Seoul National University, College of Medicine, Seoul 03080, South Korea}

\section{Authors' contributions}

H.L., J.G.K., and S.W.P. performed the research. H.L., H.J.N., J.M.K., C.Y.Y., N.S.W., and B.H.C. analyzed the data. B.K., S.I.C., and Y.M.B. designed the research study. Y.M.B. wrote the paper.

\section{Conflict of interest}

The authors declare that they have no conflict of interest.

\section{Publisher's note}

Springer Nature remains neutral with regard to jurisdictional claims in published maps and institutional affiliations

Received: 11 October 2017 Revised: 9 January 2018 Accepted: 31 January 2018.

Published online: 27 April 2018

\section{References}

1. Goodman, L. S., Hardman, J. G., Limbird, L. E. \& Gilman, A. G. Goodman \& Gilman's the Pharmacological Basis of Therapeutics. 10th edn, (McGraw-Hill, New York, NY, USA, 2001).

2. Katzung, B. G A Concise Medical Library for Practitioner and Student. (Lange Medical Publications: Los Altos, CA, USA, 1982).

3. Huettner, J. E. \& Bean, B. P. Block of N-methyl-D-aspartate-activated current by the anticonvulsant MK-801: selective binding to open channels. Proc. Natl Acad. Sci. USA 85, 1307-1311 (1988). 
4. Lewis, S. J., Barres, C., Jacob, H. J., Ohta, H. \& Brody, M. J. Cardiovascular effects of the $\mathrm{N}$-methyl-D-aspartate receptor antagonist MK-801 in conscious rats. Hypertension 13(6 Pt 2), 759-765 (1989).

5. Loscher, W., Fredow, G. \& Ganter, M. Comparison of pharmacodynamic effects of the non-competitive NMDA receptor antagonists MK-801 and ketamine in pigs. Eur. J. Pharmacol. 192, 377-382 (1991).

6. Winter, J. C., Doat, M. \& Rabin, R. A. Potentiation of DOM-induced stimulus control by non-competitive NMDA antagonists-A link between the glutamatergic and serotonergic hypotheses of schizophrenia. Life Sci. 68, 337-344 (2000).

7. Andine, P. et al. Characterization of MK-801-induced behavior as a putative rat model of psychosis. J. Pharmacol. Exp. Ther. 290, 1393-1408 (1999).

8. Kapur, S. \& Seeman, P. NMDA receptor antagonists ketamine and PCP have direct effects on the dopamine D(2) and serotonin 5-HT(2)receptors-implications for models of schizophrenia. Mol. Psychiatry 7, 837-844 (2002).

9. D'Adamo, M. C. et al. 5-HT2 receptors-mediated modulation of voltage-gated $\mathrm{K}+$ channels and neurophysiopathological correlates. Exp. Brain Res. 230 453-462 (2013).

10. Ninan, I. \& Kulkarni, S. K. 5-HT2A receptor antagonists block MK-801-induced stereotypy and hyperlocomotion. Eur. J. Pharmacol. 358, 111-116 (1998).

11. Seeman, P., Ko, F. \& Tallerico, T. Dopamine receptor contribution to the action of PCP, LSD and ketamine psychotomimetics. Mol. Psychiatry 10, 877-883 (2005).

12. Park, S. W. et al. Facilitation of serotonin-induced contraction of rat mesenteric artery by ketamine. Korean J. Physiol. Pharmacol. 20, 605-611 (2016).

13. Kim, H. S. et al. N-Methyl-D-aspartate receptor antagonists enhance the headtwitch response, a 5-hydroxytryptamine2 receptor-mediated behaviour, in reserpine-treated mice. J. Pharm. Pharmacol. 52, 717-722 (2000).

14. Kim, J. M. et al. Blockade of voltage-gated $\mathrm{K}(+)$ currents in rat mesenteric arterial smooth muscle cells by MK801. J. Pharmacol. Sci. 127, 92-102 (2015).

15. Kim, S. H. et al. Ketamine blocks voltage-gated $\mathrm{K}(+)$ channels and causes membrane depolarization in rat mesenteric artery myocytes. Pflug. Arch. 454, 891-902 (2007)

16. Bae, Y. M. et al. Serotonin depolarizes the membrane potential in rat mesenteric artery myocytes by decreasing voltage-gated K+ currents. Biochem. Biophys. Res. Commun. 347, 468-476 (2006).

17. Sung, D. J. et al. Serotonin contracts the rat mesenteric artery by inhibiting 4aminopyridine-sensitive Kv channels via the 5-HT2A receptor and Src tyrosine kinase. Exp. Mol. Med. 45, e67 (2013).

18. Cogolludo, A. et al. Serotonin inhibits voltage-gated $\mathrm{K}+$ currents in pulmonary artery smooth muscle cells: role of $5-\mathrm{HT}_{2 \mathrm{~A}}$ receptors, caveolin-1, and $\mathrm{KV} 1.5$ channel internalization. Circ. Res. 98, 931-938 (2006).

19. Brendel, J. \& Peukert, S. Blockers of the Kv1.5 channel for the treatment of atrial arrhythmias. Curr. Med. Chem. Cardiovasc. Hematol. Agents 1, 273-287 (2003).

20. Ravens, U. \& Wettwer, E. Ultra-rapid delayed rectifier channels: molecular basis and therapeutic implications. Cardiovasc. Res. 89, 776-785 (2011).
21. Attardi, B., Takimoto, K., Gealy, R., Severns, C. \& Levitan, E. S. Glucocorticoid induced up-regulation of a pituitary $\mathrm{K}+$ channel mRNA in vitro and in vivo. Recept. Channels 1, 287-293 (1993).

22. Horio, Y. Potassium channels of glial cells: distribution and function. Jpn J. Pharmacol. 87, 1-6 (2001).

23. Noh, $\mathrm{H}$. J. et al. The vasodilatory effect of ketamine is independent of the $\mathrm{N}$ methyl-D-aspartate receptor: lack of functional N-methyl-D-aspartate receptors in rat mesenteric artery smooth muscle. Eur. J. Anaesthesiol. 26, 676-682 (2009).

24. Lee, H. M., Hahn, S. J. \& Choi, B. H. Blockade of Kv1.5 by paroxetine, an antidepressant drug. Korean J. Physiol. Pharmacol. 20, 75-82 (2016).

25. Lee, H. M., Hahn, S. J. \& Choi, B. H. Blockade of Kv1.5 channels by the antidepressant drug sertraline. Korean J. Physiol. Pharmacol. 20, 193-200 (2016).

26. Swanson, R. et al. Cloning and expression of CDNA and genomic clones encoding three delayed rectifier potassium channels in rat brain. Neuron 4, 929-939 (1990)

27. Hamill, O. P., Marty, A., Neher, E., Sakmann, B. \& Sigworth, F. J. Improved patchclamp techniques for high-resolution current recording from cells and cell-free membrane patches. Pflug. Arch. 391, 85-100 (1981).

28. Lu, R. et al. c-Src tyrosine kinase, a critical component for $5-\mathrm{HT}_{2 \mathrm{~A}}$ receptormediated contraction in rat aorta. J. Physiol. 586, 3855-3869 (2008).

29. Akata, T., Izumi, K. \& Nakashima, M. Mechanisms of direct inhibitory action of ketamine on vascular smooth muscle in mesenteric resistance arteries. Anesthesiology 95, 452-462 (2001).

30. Hara, Y., Chugun, A., Nakaya, H. \& Kondo, H. Tonic block of the sodium and calcium currents by ketamine in isolated guinea pig ventricular myocytes. J. Vet. Med Sci. 60, 479-483 (1998).

31. Yamazaki, M., Ito, Y., Kuze, S., Shibuya, N. \& Momose, Y. Effects of ketamine on voltage-dependent $\mathrm{Ca}^{2+}$ currents in single smooth muscle cells from rabbit portal vein. Pharmacology 45, 162-169 (1992).

32. Becker, A. et al. Ketamine-induced changes in rat behaviour: a possible animal model of schizophrenia. Prog. Neuropsychopharmacol. Biol. Psychiatry 27, 687-700 (2003).

33. Manahan-Vaughan, D., von Haebler, D., Winter, C., Juckel, G. \& Heinemann, U. A single application of MK801 causes symptoms of acute psychosis, deficits in spatial memory, and impairment of synaptic plasticity in rats. Hippocampus $\mathbf{1 8}$, 125-134 (2008).

34. Rung, J. P., Carlsson, A., Ryden Markinhuhta, K. \& Carlsson, M. L. (+)-MK-801 induced social withdrawal in rats; a model for negative symptoms of schizophrenia. Prog. Neuropsychopharmacol. Biol. Psychiatry 29, 827-832 (2005).

35. Busatto, G. F. \& Kerwin, R. W. Perspectives on the role of serotonergic mechanisms in the pharmacology of schizophrenia. J. Psychopharmacol. 11, 3-12 (1997).

36. Gonzalez-Maeso, J. et al. Identification of a serotonin/glutamate receptor complex implicated in psychosis. Nature 452, 93-97 (2008). 